\title{
Sobre o Regime de Informação no Laboratório de Tecnologias Intelectuais - LTi
}

\author{
About Information Regime in the Laboratory Technology Intellectual - LTi
}

\begin{abstract}
Isa Maria Freire
Doutora em Ciência da Informação pela Universidade Federal do Rio de Janeiro - UFRJ. Professora e pesquisadora no Programa de Pós-Graduação em Ciência da Informação da Universidade Federal da Paraíba - UFPB.

E-mail: isafreire@globo.com
\end{abstract}

\section{Resumo}

Apresenta uma reflexão sobre o regime de informação no Projeto Laboratório de Tecnologias Intelectuais - LTi do Departamento de Ciência da Informação da Universidade Federal da Paraíba. Compartilha os primeiros resultados de pesquisa com o objetivo de acompanhar, discutir e avaliar as ações de informação em desenvolvimento no LTi e analisa as atividades a partir do modelo das ações de informação proposto por González de Gómez. Resume o quadro teórico-metodológico que abrange a abordagem do regime de informação, o escopo e procedimentos da pesquisa, e descreve a rede de projetos do LTi na perspectiva dos estratos e modalidades das ações de informação, bem como dos seus respectivos atores sociais.

Palavras-chave: Rede conceitual. Regime de informação. Ações de informação. Políticas de informação. Laboratório de Tecnologias Intelectuais - LTi.

\begin{abstract}
Presents a reflection on the information regime in the Project Technologies Laboratory Intellectuals - LTi Department of Information Science at the Federal University of Paraíba. Share the initial results of research with the aim to monitor, discuss and evaluate the actions of LTi in developing information and analyzes activities from model information actions proposed by Gonzalez Gomez. Summarizes the theoretical and methodological framework that covers the approach of information regime, the scope and procedures of the research, and describes a network of LTi projects in view of the strata, and modalities of action information, as well as their respective social actors.
\end{abstract}

Keywords: Network concept. Information regime. Shares information. Information policies. Technologies Laboratory Intellectuals - LTi. 


\section{Introdução}

Este artigo compartilha resultados de um processo de reflexão sobre as ações de pesquisa - ensino - extensão em curso no regime de informação do Projeto Laboratório de Tecnologias Intelectuais - LTi, o qual tem como objetivo desenvolver um modelo de ação de informação para produção e compartilhamento de informação e conhecimento na web, como apoio a atividades na área de Ciência da Informação. Uma comunicação a propósito da categorização dessas ações de informação foi apresentada no XIII Encontro Nacional de Pesquisa em Ciência da Informação.

O LTi iniciou suas atividades em 2009, com apoio do Conselho Nacional de Desenvolvimento Científico e Tecnológico (CNPq), através do edital Ciências Humanas CNPq - Capes 2010, dos editais Universal 2009 e 2011 e do Programa Institucional de Bolsas de Iniciação Científica (PIBIC Graduação e Ensino Médio), e do Programa de Bolsas de Extensão (MEC/Probex) da Universidade Federal da Paraíba (UFPB). O Projeto tem como propósito contribuir para a formação acadêmica nos cursos de graduação e pós-graduação da UFPB, a partir da experiência de integração de atividades de pesquisa - ensino - extensão, bem como atender a demandas de informação da sociedade em geral.

A abordagem metodológica do LTi tem um caráter participativo no espaço sócioinstitucional-virtual onde se desenvolve, tanto em nível teórico quanto em nível operacional, . Nossa rede teórica (WERSIG, 1993) tem como atrator conceitual a responsabilidade social da Ciência da Informação (WERSIG; NEVELING, 1975; FREIRE, 2001). Outros fios da rede conceitual são os construtos de regime de informação (GONZÁLEZ DE GÓMEZ, 1999, 2002, 2003, 2012, tecnologias intelectuais e inteligência coletiva (LÉVY, 1994, 2000), cultura informacional (ALA, 1989), gestão de projetos (LÜCK, 2003 FREIRE, 2004) e pesquisa-ação, como proposta por Thiollent (1997; 2000) e experimentada por Freire (1998), Espírito Santo e Freire (2004) e Freire (2006 e 2009).

Particularmente, o presente trabalho resulta de reflexão sobre o regime de informação em desenvolvimento no LTi. 


\section{Tear Conceitual}

Como urdidura para os fios do nosso texto, apresentamos, a seguir, a rede conceitual a partir da qual propomos contribuir para uma reflexão, na perspectiva da Ciência da Informação, sobre as ações de pesquisa - ensino - extensão, no espaço do LTi. Dessa forma, esperamos ampliar a discussão sobre o valor da informação na sociedade contemporânea, sobre a necessária democratização do acesso a fontes de informação na web e as competências informacionais relevantes nesse processo.

\subsection{A Trama da Rede}

Em 1993, Wersig sugeriu para a ciência da informação uma estrutura teórica que considerasse menos a formulação de leis gerais e mais a de estratégias de ação, mediante uma abordagem de entrelaçamento de conceitos científicos. Neste modelo teórico, os conceitos fundamentais

[...] se constituem semelhantemente a ímãs, ou 'atratores', atraindo os materiais [teóricos ou empíricos] para fora [dos seus respectivos campos científicos] e reestruturando-os dentro da estrutura científica da informação. (WERSIG, 1993, p. 231)

Dessa forma, seria tecida uma rede de conceitos da Ciência da Informação, a partir da qual abordagens teóricas e metodológicas poderiam se encontrar e entretecer outros fios conceituais, "fazendo a rede ainda mais inclusiva e mais apertada, de modo a aumentar seu caráter científico" (WERSIG, 1993, p.232). Nesse sentido, o autor propõe que

Desde que todas as coisas estão conectadas entre si [...] a Ciência da Informação deveria desenvolver algum tipo de sistema conceitual de navegação [...] Esta é a diferença entre o cientista da informação e um pássaro em vôo: este último já tem seus planos de vôo determinados pela evolução. No nosso caso, o passo seguinte da evolução na ciência espera para ser dado, por alguém. (WERSIG, 1993, p. 239)

Este modelo de abordagem teórica na Ciência da Informação foi aplicado por Freire (2001) para demonstrar a responsabilidade social da Ciência da Informação na sociedade contemporânea, construto que constitui o atrator conceitual do Projeto LTi e a partir do qual será urdido um contexto em cuja trama se destacam - dentre outros também relevantes —, os construtos de 'tecnologias intelectuais' e de 'regime de informação'.

Seguindo o modelo de Pierre Lévy (1994, p. 42) consideramos tecnologias intelectuais 
(p.ex., a escrita em tabuinhas de barro, as iluminuras medievais, a imprensa e os computadores). Podemos chamá-las, também, de 'tecnologias soft' em contraponto às tecnologias de produção material (que evoluíram, p.ex., desde o machado de pedra até os satélites de comunicação).

Ainda de acordo com Lévy (1994, p.42), essas tecnologias intelectuais

[...] situam-se fora dos sujeitos cognitivos, como este computador sobre minha mesa ou este [texto] em suas mãos. Mas elas também estão entre os sujeitos como códigos compartilhados, textos que circulam, programas que copiamos, imagens que imprimimos e transmitimos por via hertziana. [...] As tecnologias intelectuais estão ainda nos sujeitos, através da imaginação e da aprendizagem. (grifo nosso).

No modelo em aplicação no LTi, o construto de 'responsabilidade social da Ciência da Informação' tem um papel central entre os demais conceitos da rede, os quais assumem funções teórica ou interpretativa, como no caso dos construtos 'rede conceitual', 'regime de informação' e 'inteligência coletiva'; metodológica, como no caso do construto 'pesquisaação'; ou operacionais, como no caso dos construtos 'tecnologias intelectuais' e 'cutura informacional'. Na figura 1, a seguir, descrevemos a rede conceitual do Projeto LTi:

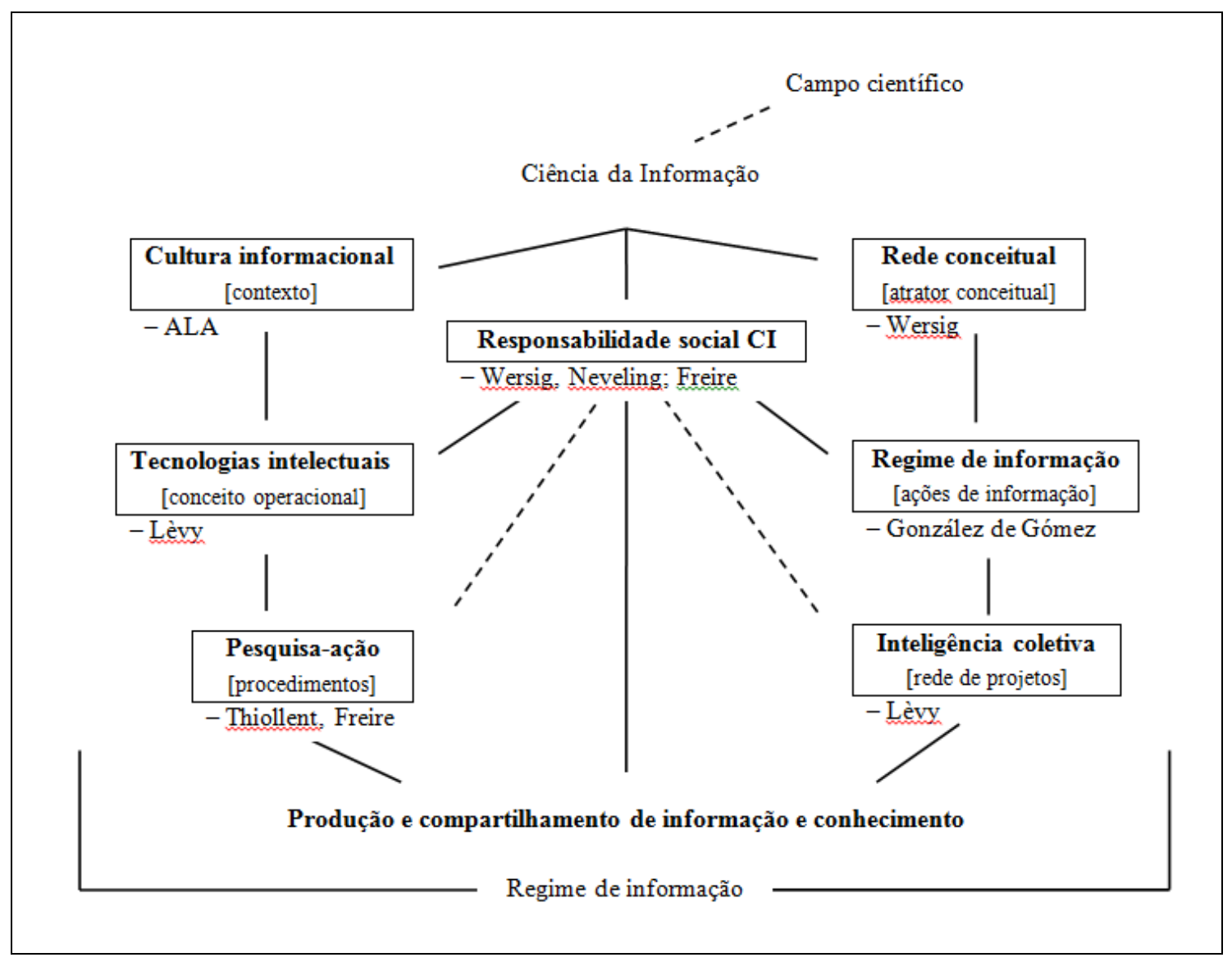

Figura 1 - Rede conceitual do Projeto LT $i$

Fonte: Adaptado de Wersig, 1993. FREIRE, 2011. 
Como não poderia deixar de ser, a trama da nossa rede conceitual é tecida no espaço social da contemporaneidade, que se realiza no mundo da vida das sociedades humanas e no mundo virtual das comunidades constituídas no ciberespaço ${ }^{1}$ mediante a Internet.

\title{
2.2 A ambiência do Regime de Informação
}

Atualmente, sem dúvida, podemos dizer que a noção do senso comum sobre a principal característica da sociedade em que vivemos, qual seja a abundância da informação possibilitada pelas tecnologias de informação e comunicação, em especial a Internet. Na interpretação de Unger e Freire (2008), trata-se de um sistema social que resulta de inovações nas tecnologias de informação e comunicação, as quais, em conjunto com a relevância da informação, provocaram profundas alterações nos diversos setores da sociedade, embora sua importância e influência seja desigualmente distribuída nos diferentes estratos sociais e regiões geográficas.

\begin{abstract}
Nessa nova ordem econômica mundial, que se anuncia nas explanações científicas e na economia das tecnologias digitais, é que ocorre a "nova relevância de um fenômeno antigo" (WERSIG e NEVELING, 1975 citados por Freire, 2001) e o regime de informação, com seus sistemas de informação e linguagens documentárias, inicia sua hegemonia sobre o regime industrial, na sociedade contemporânea. (UNGER; FREIRE, 2008, p. 85. grifo nosso)
\end{abstract}

Para Frohmann (1995), que trabalha esse construto com o apoio da Teoria do AtorRede de Bruno Latour, o regime de informação pode ser definido como "qualquer sistema estável ou rede nos quais os fluxos informacionais transitam por determinados canais [de específicos produtores, via estruturas organizacionais específicas] para consumidores ou usuários específicos" (UNGER; FREIRE, 2008, p. 87). Nessa perspectiva, redes de rádio e televisão, distribuidoras de filmes, publicações acadêmicas, bibliotecas, se constituem em nós de redes de informação ou elementos de regimes de informação específicos. Considerando a relevância dos regimes de informação na sociedade contemporânea, Frohmann (1995) afirma que os estudos visando sua clara representação - como se originam e se estabilizam, como determinam as relações sociais e como são exercidas as formas de poder em e através deles se apresenta como um "legítimo e premente objetivo na pesquisa em política de informação". Para o autor,

\footnotetext{
1 Para Lévy (1999, p.36, grifo do autor), “o ciberespaço [também chamado de rede] é o novo meio de comunicação que surge da interconexão mundial dos computadores. O termo especifica não apenas a infraestrutura material da comunicação digital, mas também o universo oceânico de informações que ela abriga, assim como os seres humanos que navegam e alimentam esse universo."
}

InCID: R. Ci. Inf. e Doc., Ribeirão Preto, v. 4, n. 1, p. 70-86, jan./jun. 2013. 
[...] Descrever um regime de informação significa catalogar [mapear] o polêmico processo que resulta da tentativa da inquieta estabilização dos conflitos entre os grupos sociais, interesses, discursos, com os eqüitativos artefatos científicos e tecnológicos. A estrutura teórica do estudo das políticas de informação, deve ser suficientemente rica para compreender as complexidades destas relações. (FROHMANN, 1995)

González de Gómez, por sua vez, trabalha o conceito de regime de informação na concepção de dispositivo ${ }^{2}$ de Michel Foucault, definindo-o como

[...] modo informacional dominante em uma formação social, o qual define quem são os sujeitos, as organizações, as regras e as autoridades informacionais e quais os meios e os recursos preferenciais de informação, os padrões de excelência e os modelos de sua organização, interação e distribuição, enquanto vigente em certo tempo, lugar e circunstância. Como um plexo de relações e agências, um regime de informação está exposto a certas possibilidades e condições culturais, políticas e econômicas, que nele se expressam e nele se constituem. (GONZÁLEZ DE GÓMEZ, 2012, p. 43)

Destarte, a abordagem de regimes de informação apresenta diferenças em Frohmann e em González de Gómez, pois enquanto o primeiro se aborda os artefatos tecnológicos e a viabilidade do trânsito informacional por e através do meio físico, a última aborda o regime de informação sob os aspectos político e gerencial. Nesse sentido, acompanhamos a interpretação de Unger e Freire (2008) quando destacam, na abordagem de González de Gómez, que é no meio ambiente de trocas materiais (econômicas, tecnológicas, culturais) que ocorrem as relações entre os seres humanos com necessidades informacionais e as fontes de informação e conhecimento relevantes. Os autores acrescentam que regimes são compostos fisicamente por:

- estoques de informação (produzidos e disseminados no escopo dos sistemas de informação);

- diretrizes políticas e práticas de gestão que direcionam e organizam os conteúdos informacionais abrigados nos sistemas de informação;

- seres humanos e suas necessidades informacionais;

- ambiente social em que os estoques de informação e os seres humanos que os utilizam se inserem;

- os mecanismos de distribuição do acesso à informação;

- os meios físicos que permitem o ir e vir da informação (unidades de informação, rede Internet). (UNGER; FREIRE, 2008 p.101)

Utilizando um recurso gráfico, Delaia (2008) reuniu e descreveu os elementos de um regime de informação, destacando as relações entre os seus componentes, como segue:

\footnotetext{
${ }^{2}$ Etimologicamente, o termo latino dispositio seria a tradução do termo grego diathesis. Na filosofia moderna, é definido como aquilo que facilita, faz algo possível ou limita as possibilidades de algo.
}

InCID: R. Ci. Inf. e Doc., Ribeirão Preto, v. 4, n. 1, p. 70-86, jan./jun. 2013. 


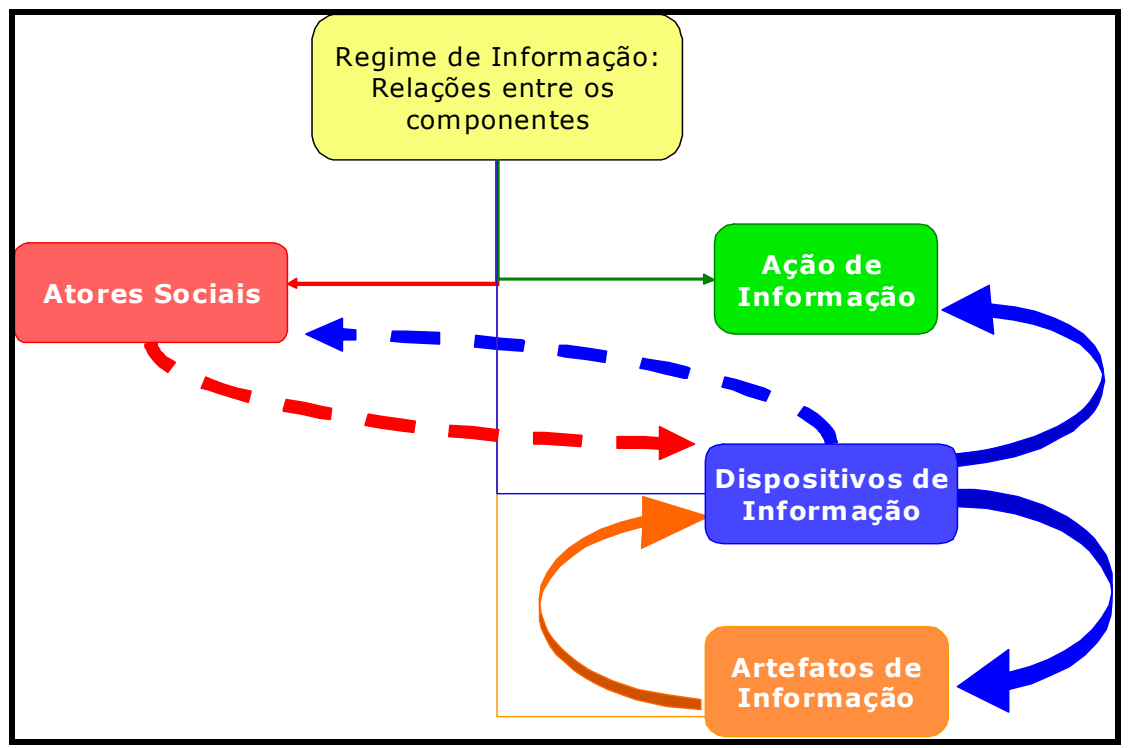

Figura 2 - Representação gráfica dos componentes do regime de informação Fonte: DELAIA, 2008.

A autora descreve esses componentes, a partir de suas respectivas definições por González de Gómez:

a) Os Dispositivos de informação, os quais podem ser considerados um mecanismo operacional, ou um conjunto de meios composto de regras de formação e de transformação desde o seu início, ou como a autora exemplifica, como "um conjunto de produtos e serviços de informação e das ações de transferência de informação" (GONZÁLEZ DE GÓMEZ, 1999, p. 63);

b) Os Atores sociais, "[que] podem ser reconhecidos por suas formas de vidas e constroem suas identidades através de ações formativas existindo algum grau de institucionalização e estruturação das ações de informação". (GONZÁLEZ DE GÓMEZ, 2003b, p. 35).

c) Os Artefatos de informação, que constituem os modos tecnológicos e materiais de armazenagem, processamento e de transmissão de dados, mensagem, informação. (GONZÁLEZ DE GÓMEZ, 2002, 2003b).

Neste modelo, e enquanto ação de informação, a informação refere-se a um conjunto de estratos heterogêneos e articulados, que se manifestam através de três modalidades de ação, conforme apresentado no quadro 1, a seguir: 
Quadro 1 - Teleologia das ações de informação

\begin{tabular}{|l|l|l|l|}
\hline \multicolumn{1}{|c|}{$\begin{array}{c}\text { Ações de } \\
\text { Informação }\end{array}$} & \multicolumn{1}{|c|}{ Atores } & \multicolumn{1}{c|}{ Atividades } & \multicolumn{1}{c|}{ [Finalidade] } \\
\hline Ação de Mediação & $\begin{array}{l}\text { Sujeitos Sociais } \\
\text { Funcionais }\left(\text { práxis }^{3}\right)\end{array}$ & $\begin{array}{l}\text { Atividades } \\
\text { Sociais Múltiplas }\end{array}$ & $\begin{array}{l}\text { Transformar o mundo } \\
\text { social ou natural }\end{array}$ \\
\hline $\begin{array}{l}\text { Ação Formativa ou } \\
\text { Finalista }\end{array}$ & $\begin{array}{l}\text { Sujeitos Sociais } \\
\text { Experimentadores } \\
\left.\text { poiesis }^{4}\right)\end{array}$ & $\begin{array}{l}\text { Atividades } \\
\text { Heurísticas e de } \\
\text { Inovação }\end{array}$ & $\begin{array}{l}\text { Transformar o } \\
\text { conhecimento para } \\
\text { transformar o mundo }\end{array}$ \\
\hline $\begin{array}{l}\text { Ação Relacional } \\
\text { Inter-Meta-Pós- } \\
\text { mediática }\end{array}$ & $\begin{array}{l}\text { Sujeitos Sociais } \\
\text { Articuladores e } \\
\text { Reflexivos (legein }\end{array}$ & $\begin{array}{l}\text { Atividades } \\
\text { Sociais de } \\
\text { Monitoramento, } \\
\text { Controle e } \\
\text { Coordenação }\end{array}$ & $\begin{array}{l}\text { Transformar a } \\
\text { informação e a } \\
\text { comunicação que } \\
\text { orientam o agir coletivo }\end{array}$ \\
\hline
\end{tabular}

Fonte: González de Gómez (2003a, p. 37).

Nesse contexto, concordamos com Unger e Freire (2008, p. 85) em que os regimes de informação "são a substância que dão o caráter principal a um sistema social que passou por diferentes e longas fases até chegar ao estágio atual”. E se, como interpreta González de Gómez (2002, p. 85), a ‘sociedade da informação’ pode ser entendida como aquela em que “o regime de informação caracteriza e condiciona todos os outros regimes sociais, econômicos, culturais, das comunidades e do Estado",

[...] o ser social que 'migrou' da Sociedade industrial para a Sociedade da informação deve ter condições de responder aos novos imperativos relativos a esta nova estrutura de relações e de produção. E este ser social necessita de suporte informacional para que possa realizar suas aspirações e aquelas que a própria sociedade demanda. (UNGER; FREIRE, 2008, p. 86),

Para a American Library Association - ALA, o ideal é contribuir para criar uma 'cultura informacional', que é vista como um conjunto de aptidões desenvolvidas para a resolução de problemas de informação - localizar, avaliar e usar a informação com eficácia e efetividade (UNGER; FREIRE, 2008). Nesse sentido, a estrutura em redes mediada pela Internet é imprescindível para o atendimento às necessidades informacionais e a perspectiva de um olhar global sobre os recursos locais de um dado regime de informação - neste caso a

\footnotetext{
${ }^{3}$ Práxis - No campo científico, entende-se como uma prática profissional em que os atores sociais atuam a partir de uma teoria que é a base para sua ação no mundo.

${ }^{4}$ Poiesis - "Diz-se quando a ação de informação no contexto formativo é gerada por sujeitos sociais heurísticos ou 'experimentadores', transformando os modos culturais de agir e de fazer, nas artes, na política, na ciência, na indústria e no trabalho, iniciando um novo domínio informacional.” (GONZÁLEZ DE GÓMEZ, 2003a, p. 36).

${ }^{5}$ Legein - "Diz-sequando uma ação de informação intervem em [uma] outra [...], duplicando o espaço de realização [desta, de modo a ampliar as] formas de descrição, da facilitação, do controle ou do monitoramento, [...] realizadas por sujeitos articuladores ou relacionantes." (GONZÁLEZ DE GÓMEZ, 2003a, p. 36).
} 
Universidade Federal da Paraíba — resultará em benefícios na participação de todos na sociedade da informação.

\subsection{Informação/Ação de informação no Regime de Informação}

O construto de 'regime de informação', proposto por González de Gómez (1999; 2002; 2003; 2004), designa o modo de produção informacional numa formação social, no qual ficaria estabelecido quem são os sujeitos, as organizações, as regras e as autoridades normativas no campo da informação. Trata-se do conjunto de determinações onde estão definidos os elementos que compõem o fluxo estrutural da produção, organização, comunicação e transferência de informações em um dado espaço social. Nesta perspectiva, a Ciência da Informação

[é] aquela que estuda fenômenos, processos, construções, sistemas, redes e artefatos de informação, enquanto 'informação' for definida por ações de informação, as quais remetem aos atores que as agenciam aos contextos e situações em que acontecem e aos regimes de informação em que se inscrevem. (GONZÁLEZ DE GÓMEZ, 2003b, p. 61. Itálico nosso)

Assim posto, a autora analisa a informação/ação de informação na perspectiva de que estas constituem um conjunto de estratos heterogêneos e articulados, a saber:

a) de informação (semântico-pragmática), estrato polimórfico que se define nos inúmeros setores da produção social sob a forma de ações narrativas;

b) de meta-informação, estrato regulatório definido nos espaços institucionais do Estado, do campo científico, da educação formal, da legislação e dos contratos;

c) de infra-estruturas de informação, estrato mimeomórfico dos objetos de informação, "definido na indústria e nos mercados das tecnologias, das máquinas e dos produtos" mediante "ações tecnoeconômicas, normas técnicas modelos" (GONZÁLEZ DE GÓMEZ, 2003a, p.34).

Nesse ponto de sua argumentação, González de Gómez (2003b, p.36) se propõe “melhorar essa conceitualização da informação pela reconstrução do que sejam 'ações de informação', relacionando 'ação social' e 'forma de vida', [tal como propostas por Harry Collins]", entendendo ${ }^{6}$ "que uma 'forma de vida' pode estar constituída pelas interações duradouras de um grupo que partilha de atividades, situações e experiências comuns". Sua proposta de trabalho, baseada em Collins e Kush (1999), considera que as 'ações formativas' "são aquelas constitutivas de uma 'forma de vida', a qual singularizam e diferenciam em relação a outros modos de ação e formas de vida" (GONZÁLEZ DE GÓMEZ, 2003b, p.36). Assim,

\footnotetext{
${ }^{6}$ Cf. GEERTZ, 1998.
}

InCID: R. Ci. Inf. e Doc., Ribeirão Preto, v. 4, n. 1, p. 70-86, jan./jun. 2013. 
Uma ação formativa, por exemplo, na academia, é apresentar uma comunicação num congresso. O que 'fixa' um significado, um discurso, ou pode pré-configurar um 'artefato de informação' em alguma de suas dimensões, não seria logo e em primeiro lugar a base material da inscrição, e sim as condições institucionais e as relações socioculturais entre os sujeitos - incluídas as relações de poder que articulam os artefatos e as infraestruturas de informação em regimes de informação. (GONZÁLEZ DE GÓMEZ, 2003b, p.36)

A autora concorda com Collins e Kush (1999, p.19) em que estratos ou dimensões das ações de informação admitem outra leitura, conforme se trate de ações polimórficas ou ações mimeomórficas, esclarecendo que

Ações polimórficas são aquelas que só podem ser compreendidas por quem participa de uma cultura ou forma de vida. Nesse caso, a mesma ação, na mesma situação, pode ser executada conforme um número indefinido de comportamentos $\mathrm{e}$, ao mesmo tempo, uma mesma instância de comportamento pode dar lugar a muitas e diferentes ações. Dado que são ações determinadas por regras, o modo "correto" de praticá-las só é possível para quem participa da forma de vida que é o contexto da ação. [...] (GONZÁLEZ DE GÓMEZ, 2003b, p.34)

Por sua vez,

Ações mimeomórficas seriam aquelas que poderiam ser reproduzidas tanto por um observador externo - alguém que não compreende sua intencionalidade nem seu contexto de geração -, quanto por quem compreende a ação (COLLINS; KUSH, 1999, p.21). São tipos de ações pré-modeladas que podem apreender-se através de exemplos, por treinamento. Tal como discar num telefone ou 'clicar' um ícone do Windows. (GONZÁLEZ DE GÓMEZ, 2003b, p.34)

A partir da abordagem de Collins, González de Gómez (2003, p.36) reconhece três modalidades de manifestação de uma ação de informação, conforme o contexto de sua constituição em um dado regime de informação:

a) ação de informação de mediação (quando a ação de informação fica atrelada aos fins e orientação de uma outra ação);

b) ação de informação formativa (aquela que é orientada à informação não como meio mas como sua finalização);

c) ação de informação relacional (quando uma ação de informação tem como finalidade intervir numa outra ação de informação, de modo que - ainda quando de autonomia relativa - dela obtém a direção e fins)

Destarte, as ações de pesquisa e as ações de informação integram um mesmo domínio de orientações estratégicas e, como consequência, "a política e a gestão da informação formarão parte do mesmo plano decisional e prospectivo ao qual pertence a política e a gestão da ciência e tecnologia" (GONZÁLEZ DE GÓMEZ, 2003a, p. 61). 


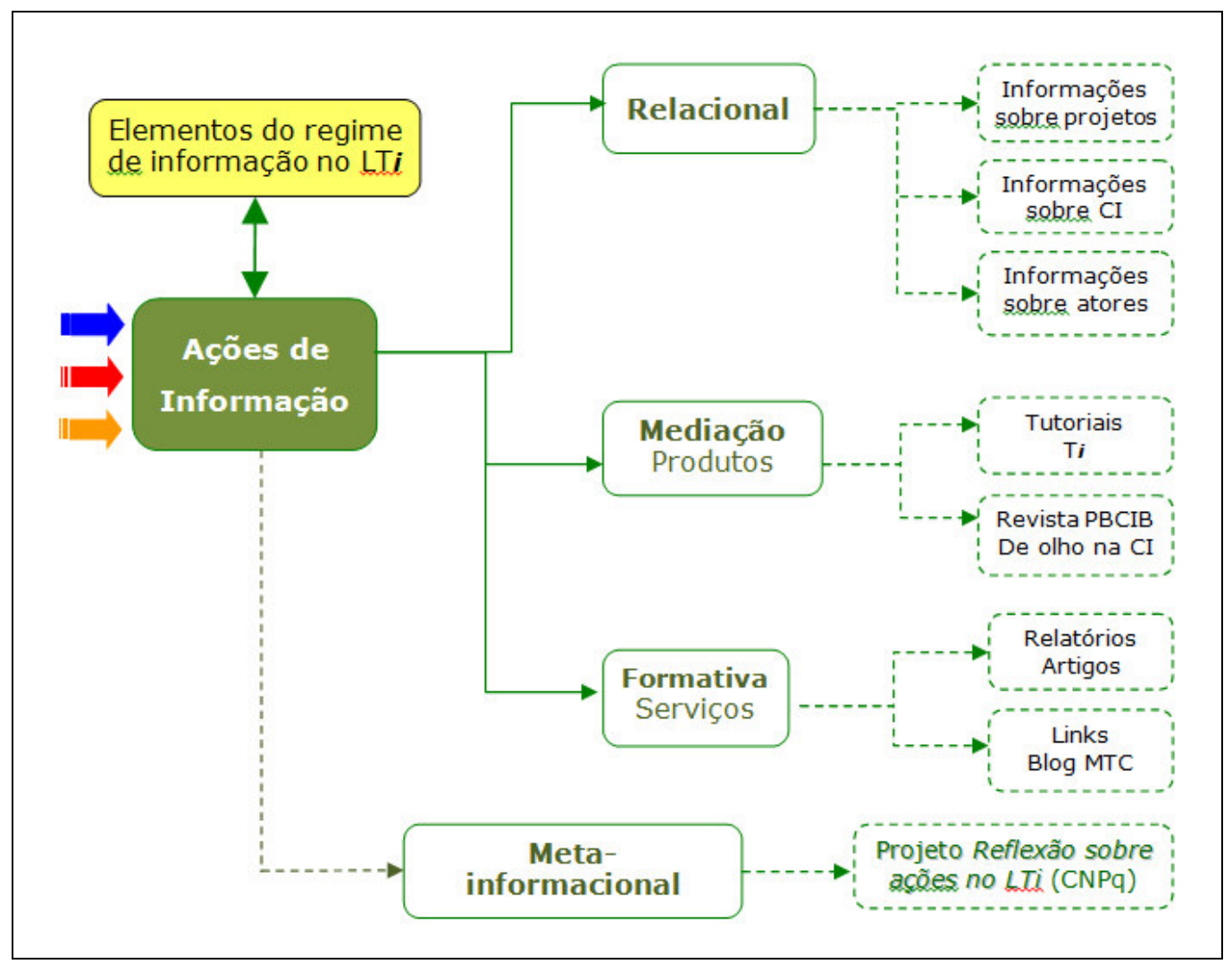

Figura 3 - Descrição das modalidades de ações de informação no LTi Fonte: FREIRE, I.M. Notas de trabalho, jan. 2013.

Em nível operacional, o LTi é implementado através de uma rede de projetos, em correspondência às atividades acadêmicas da UFPB e em conformidade com o 'método de projeto', considerado por Lück (2003) como uma "ferramenta básica do gestor, que [...] fundamenta, direciona e organiza a ação de sua responsabilidade [e] possibilita o seu monitoramento e avaliação" (LUCK, 2003, p.13). Nesta perspectiva, 'projeto' é definido como

[...] um conjunto organizado e encadeado de ações de abrangência e escopo definidos, que focaliza aspectos específicos a serem abordados num período determinado de tempo, por pessoas associadas e articuladoras das condições promotoras de resultados. (LÜCK, 2003 apud FREIRE, 2004, p. 83)

A seguir, a figura 4 descreve a rede de projetos do LTi: 


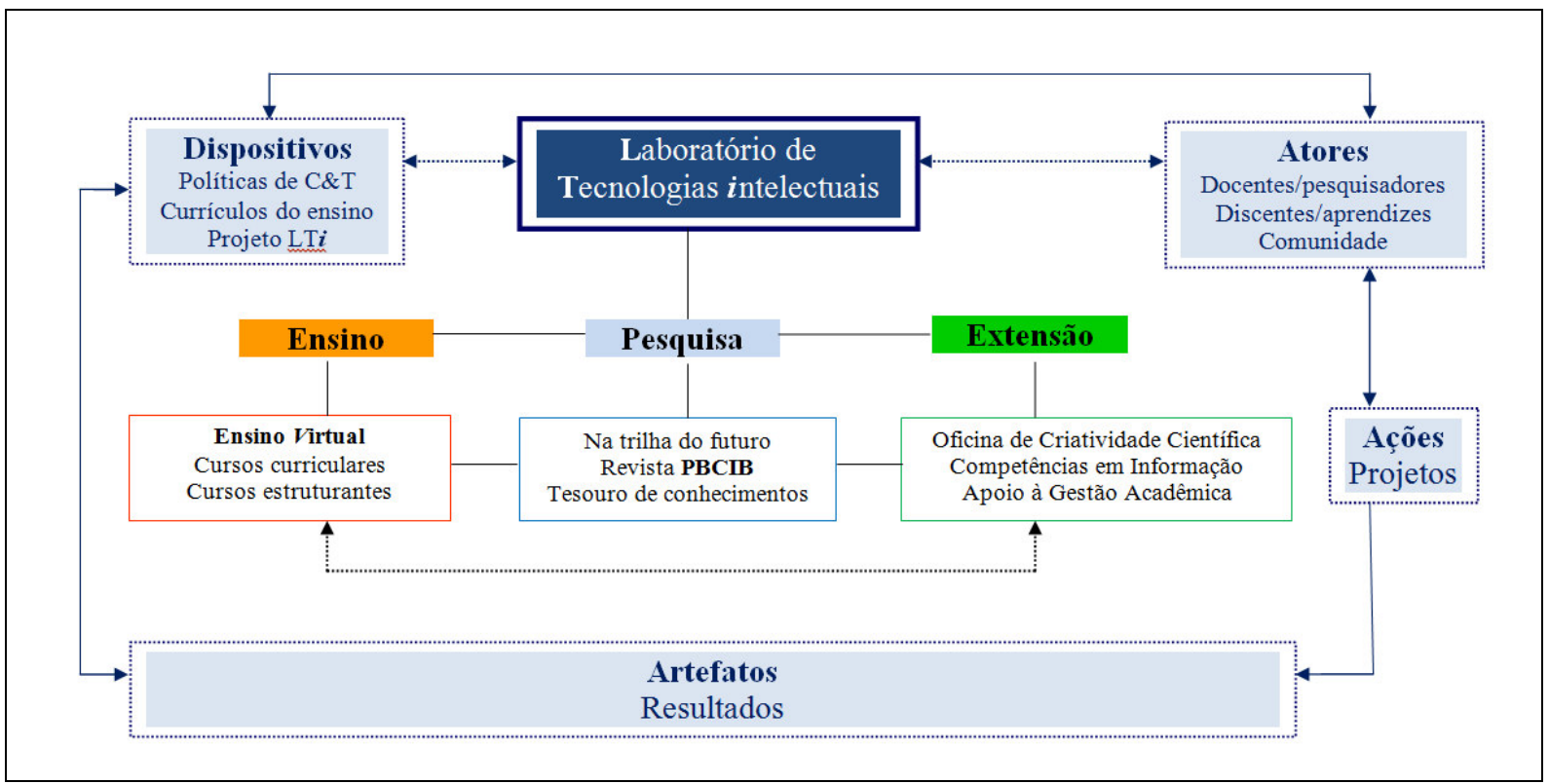

Figura 4 - Rede de projetos do LT $i$

Fonte: FREIRE, 2012. Projeto LTi. Acompanhamento.

Concordamos com González de Gómez em que essa abordagem singulariza a Ciência da Informação no campo científico e a coloca "numa posição preferencial para fortalecer o olhar comunicacional e gnosiológico em processos e domínios que até agora têm sido explicitados à luz de fatores econômicos ou tecnológicos" (GONZÁLEZ DE GÓMEZ, 2003b, p.38).

Com este modelo de abordagem, argumentamos que o campo da Ciência da Informação pode proporcionar recursos teóricos e tecnológicos que promovam as competências necessárias para a socialização da informação. Neste caso, é possível propor uma ação que possibilite a união desses contextos em um espaço social onde cientistas e profissionais da informação possam desenvolver ações com vistas à gestão de recursos para promover a inclusão na Sociedade da Informação e do Conhecimento.

Assim, as ações da rede de projetos para disseminação, produção e comunicação da informação contribuem, conforme modelo teórico-operativo descrito, para o desenvolvimento de habilidades de busca, recuperação, propagação e apropriação de informações relevantes por usuários na sociedade - quadro de referência em que se fundamenta a proposta do LTi. 


\section{Ações de Informação no LTi}

Os objetivos propostos nos auxiliaram na tarefa de identificar as características das ações de informação em desenvolvimento no LTi, conforme descritas no modelo de González de Gómez. Nos três níveis de atividades do LTi, a rede de projetos visa alcançar os seguintes objetivos:

a) na pesquisa - propor, experimentar e avaliar um modelo de ação de informação para promover o compartilhamento de recursos de informação e a comunicação científica sobre a proposta e resultados (eventos, publicações);

b) no ensino - contribuir, de forma propositiva, para qualidade do trabalho acadêmico nas disciplinas curriculares da graduação e pós-graduação;

c) na extensão - promover oportunidades para transferência de tecnologias intelectuais, mediante oficinas presenciais e tutoriais on line para competências em informação, bem como prestação de serviços de referência na web.

Nesse sentido, observamos que as atividades podem ser vistas como "ações de informação, as quais remetem aos atores que as agenciam, aos contextos e situações em que acontecem e aos regimes de informação em que se inscrevem”, como esclarece González de Gómez (2003b, p.31) sobre o campo de interesse da Ciência da Informação. Ademais, o uso de termos como "compartilhamento de recursos de informação", "contribuir de forma propositiva" e "promover oportunidades para transferência de tecnologias intelectuais" nos dá pistas sobre o pressuposto dessas atividades, qual seja a responsabilidade social da Ciência da Informação, na sociedade contemporânea.

Com relação à caracterização dos estratos dessas atividades enquanto ações de informação, devemos lembrar que esses estratos são heterogêneos e articulados, ocorrendo "de modo paralelo e simultâneo ao longo de todo o desenvolvimento de uma atividade ou processo" (GONZÁLEZ DE GÓMEZ, 2003b, p.33). Ou seja, no presente trabalho, a caracterização em um ou outro estrato específico tem uma finalidade heurística, auxiliando na percepção da aplicação das categorias teóricas à prática da pesquisa e desenvolvimento.

Assim, na perspectiva do estrato de informação (semântico-pragmático), trata-se de projeto direcionado ao setor científico e tecnológico da produção social, particularmente à comunidade acadêmica e aos profissionais da informação. Nesse sentido, o aspecto 
polimórfico da ação expressa as "heterogeneidades e singularidades dos [mundos de vida] dos sujeitos”, como esclarece González de Gómez (2003b, p.34) em relação às características desse estrato, procurando atender docentes, discentes, pesquisadores e profissionais técnicos.

$\mathrm{Na}$ perspectiva do estrato de meta-informação, as atividades da rede de projetos do LTi se inserem nos espaços institucionais do Estado (mediante as políticas governamentais de fomento à Ciência e Tecnologia), do campo científico (sendo um projeto de pesquisa), da educação formal (vinculado a instituição de ensino superior), da legislação (práticas são orientadas por regulamentos) e dos contratos (termos de concessão de recursos). É nesse domínio regulatório que

[...] se estipula o domínio relacional [...] dentro do qual algo apresenta ou representa um valor de informação [...] o contexto a partir do qual aquilo que adquire caráter de informação pode desenvolver valores cognitivos, constituir evidências probatórias, servir de apoio a decisão ou ser insumo de ações instrumentais. (GONZÁLEZ DE GÓMEZ, 2003b, p. 35).

Esse estrato é representado pelas atividades de pesquisa propriamente ditas, que concorreram a apoio institucional através de editais públicos de instituições de fomento à Ciência e Tecnologia e estão apoiadas em contratos de alocação de recursos, ou de programas específicos de apoio à atividade acadêmica na UFPB, concorrendo em programas de bolsas para graduação e pós-graduação. Este é o domínio relacional onde o Projeto LTi assume sua feição de informação em si, atendendo aos objetivos propostos nos três níveis da atividade universitária, quais sejam ensino - pesquisa - extensão, criando, nesse processo, evidências comprobatórias sobre a validade dos pressupostos teóricos da pesquisa e dos seus resultados na sociedade.

Por fim, o estrato mimeomórfico da infra-estruturas de informação, "definido na indústria e nos mercados das tecnologias, das máquinas e dos produtos [... mediante ações tecnoeconômicas, normas técnicas, modelos" (GONZÁLEZ DE GÓMEZ, 2003b, p. 34), diz respeito aos objetos de informação criados pelas atividades do LTi, dos quais o sítio virtual é o principal representante. ${ }^{7}$ Este estrato

Remete àquilo que disponibiliza e deixa disponível, como sua mediação sóciocultural, um valor de informação, e que poderíamos caracterizar como ação tecnoeconômica - de antecipação estruturante na configuração da ação/informação. [...]. (GONZÁLEZ DE GÓMEZ, 2003b, p. 35)

Dessa forma, o Projeto LTi se caracteriza como uma informação/ação de informação de interesse para o campo da informação, compreendendo uma ação social direcionada para

\footnotetext{
${ }^{7}$ Disponível em <http://dci.ccsa.ufpb.br/lti>.

InCID: R. Ci. Inf. e Doc., Ribeirão Preto, v. 4, n. 1, p. 70-86, jan./jun. 2013.
} 
uma 'forma de vida' constituída "pelas interações duradouras de um grupo que partilha de atividades, situações e experiências comuns", conforme González de Gómez (2003b, p.36) no campo da Ciência da Informação.

Ademais, trata-se de uma 'ação formativa' no sentido de Collins e Kush (1999), descrita por González de Gómez (2003) como aquela que é constitutiva de uma 'forma de vida' de um grupo, o qual singulariza e diferencia em relação a outros modos de ação e 'formas de vida'. Nesse contexto, "os atores sociais [sujeitos] estão de acordo em seus conceitos porque [...] partilham uma realidade de ações possíveis e estão de acordo em suas ações porque [...] partilham uma rede comum de conceitos" (COLLINS; KUSH, 1999, p.11 citados por GONZÁLEZ DE GÓMEZ, 2003b, p.36).

Essa rede comum se traduz, efetivamente, em uma 'cultura informacional' compartilhada pelos atores sociais envolvidos em todos os níveis de atividade do LTi, os quais constituem a 'forma de vida' dessa comunidade.

Dessa forma, as ações desenvolvem entre os participantes uma sinergia para o trabalho a ser empreendido, além de gerar comprometimento com a efetiva construção de condições para sua realização, com o propósito de promover benefícios às pessoas e organizações. Representa, também, a oportunidade para as pesquisadoras proponentes tecerem, no tear da Ciência da Informação, um padrão que (re)una informação e computação em nível da integração entre pesquisa - ensino - extensão, na práxis acadêmica.

\section{Referências}

AMERICAN LIBRARY ASSOCIATION. Presidential Committee on Information Literacy. Chicago: ALA, 1989. Final report. Disponível em: <http://www.ala.org/acrl/nili/ilit1st.html. Acesso em 2001>. Acesso em: 26 ago. 2006.

COLLINS, H. M.; KUSH, M. The shape of actions: what humans and machines can do. Cambridge, Mass: MIT Press, 1999. p. 11-21.

DELAIA, C. R. Subsídios para uma política de gestão da informação na EMBRAPA solos. 2008. Dissertação (Mestrado em Ciência da Informação)-UFF, IBICT, Niterói, 2008.

ESPÍRITO SANTO, C.; FREIRE, I. M. “Quissamã somos nós!”: construção participativa de hipertexto. Ciência da Informação, Brasília, v. 33, n. 1, p.155-168, jan./abr. 2004. 
FREIRE, G. H. A. A construção de instrumento para comunicação de informação sobre saúde. 1998. Dissertação (Mestrado em Ciência da Informação) - IBICT, UFRJ, Rio de Janeiro, 1998.

Comunicação da informação em redes virtuais de aprendizagem. 2004. Tese (Doutorado em Ciência da Informação)-IBICT, UFRJ, Rio de Janeiro, 2004.

FREIRE, I. M. A responsabilidade social da ciência da informação e/ou o olhar da consciência possível sobre o campo científico. 2001. Tese (Doutorado em Ciência da Informação)- IBICT, UFRJ, Rio de Janeiro, 2001.

A rede de projetos do Núcleo Temático da Seca da UFRN como possibilidade de socialização da informação. Informação \& Sociedade: Estudos, João Pessoa, v.14, n.2, 2004.

Acesso à informação e identidade cultural: entre o global e o local. Ciência da Informação, Brasília, v. 35, n. 2, p. 58-67, maio/ago. 2006.

Janelas da cultura local: abrindo oportunidades para inclusão digital: relatório final. Rio de Janeiro: IBICT: CNPq, 2009.

Projeto Laboratório de Tecnologias Intelectuais - Lti: relatório 2009-2011. João Pessoa: DCI: PPGCI: UFPB, 2011. Disponível em: $<$ http://dci.ccsa.ufpb.br/lti/?download=LTi_CNPq_Universal_2009_Relatorio_tecnico.pdf $>$.

Caracterização das ações de informação no Laboratório de Tecnologias Intelectuais LTi. In: ENCONTRO NACIONAL DE PESQUISA EM CIÊNCIA DA INFORMAÇÃO, 13, 2012, Rio de Janeiro. Anais..., Rio de Janeiro: IBICT: Fiocruz, 2012. Disponível em: $<$ http://www.eventosecongressos.com.br/metodo/enancib2012/anais/index.php\#eixo299_89>.

Projeto Laboratório de Tecnologias Intelectuais - LTi. João Pessoa: DCI: PPGCI: UFPB, 2013. Notas de trabalho. Documento restrito.

FROHMANN, B. Taking information policy beyond information science: applying actor network theory. In: ANNUAL CONFERENCE OF THE CANADIAN ASSOCIATION FOR INFORMATION SCIENCE, 23., 1995, Edmonton. Electronic proceddings... Edmonton, 1995. 14 p. Disponível em: <http://www.cais-acsi.ca/1995proceedings.htm ou http://www.fims.uwo.ca/people/faculty/frohmann/actor.htm>. Acesso em: 10 maio 2005.

GEERTZ, C. O saber local. Petrópolis: Vozes, 1998.

GONZÁLEZ DE GÓMEZ, M. N. Regime de informação: construção de um conceito. Informação \& Sociedade, João Pessoa, v. 22, n. 3, p.43-60, 2012.

Novas fronteiras tecnológicas das ações de informação: questões e abordagens.

Ciência da Informação, Brasília, v.33, n.1, 2004.

. As relações entre ciência, Estado e sociedade: um domínio de visibilidade para as questões da informação. Ciência da Informação, Brasília, v. 32, n. 1, p. 60-76, 2003 a. 
Escopo e abrangência da Ciência da Informação e a Pós-Graduação na área: anotações para uma reflexão. Transinformação, Campinas, v. 15, n.1, p.31-43, 2003b.

. Novos cenários políticos para a informação. Ciência da Informação, Brasília, v. 31, n. 1, p. 27-40, 2002.

Da política de informação ao papel da informação na política contemporânea.

Revista Internacional de Estudos Políticos, v. 1, n. 1, p. 57-93, 1999.

LÈVY, P. A inteligência coletiva: por uma antropologia do ciberespaço. 3. ed. São Paulo: Loyola, 2000.

. Cibercultura. São Paulo: 34, 1999.

As tecnologias da inteligência: o futuro do pensamento na era da informática. Rio de Janeiro: 34, 1994.

LÜCK, H. Metodologia de projetos: uma ferramenta de planejamento e gestão. 2. ed. Petrópolis: Vozes, 2003.

THIOLLENT, M. Metodologia da pesquisa-ação. 10. ed. São Paulo: Cortez, 2000.

Pesquisa-ação nas organizações. São Paulo: Atlas, 1997.

UNGER. R. J. G.; FREIRE, I. M. Regimes de informação na sociedade da informação: uma contribuição para a gestão de informação. Revista Digital de Biblioteconomia e Ciência da Informação, Campinas, v. 4, n. 1, p. 87-114, jan./jun. 2008.

WERSIG, G. Information science: the study of postmodern knowledge usage. Information Processing \& Management, v. 29, n. 2, p. 230-242, 1993.

WERSIG, G., NEVELING, U. The phenomena of interest to information science. The Information Scientist, v. 9, n. 4, p. 178-201, 1975. 